\title{
Cardiac resynchronization therapy improves heart failure in one patient with acromegaly-induced cardiomyopathy: a case report
}

Jun yi Wang, Yong mei Hu*, Jian xiong Liu and Xiao jia Luo

\begin{abstract}
Background: Congestive heart failure is rarely observed in patients with acromegaly. Excessive growth hormone secretion and elevation of insulin-like growth factor 1 contribute to pathological changes in myocyte growth and structure, cardiac contractility, vascular function, and in later stage may progress to cardiac dysfunction. Early recognition of the condition is paramount, though the insidious progression of the disease commonly results in late diagnosis. Current standard regimens of pharmacological therapy, surgical treatment, radiotherapy are designed to normalize serum levels of both insulin-like growth factor 1 and growth hormone. In patients with late-stage heart failure due to acromegalic cardiomyopathy, cardiac resynchronization therapy might be a desirable treatment to help cardiac synchronization, improve symptoms, and eventually reduce hospital admissions together with mortality rates.

Case presentation: We describe a case of a 49-year-old man with a history of acromegaly who presented to our hospital with a diagnosis of decompensated systolic heart failure. Serial electrocardiograms showed wide (160-200 ms) QRS duration with left bundle branch block. Echocardiography showed severe left ventricular dysfunction that simultaneously achieved a left ventricular ejection fraction of $16 \%$. Surgical indication was rarely assessed by neurosurgeons. Given that the stereotactic radiosurgery together with pharmacotherapy produced infinitesimal effects, cardiac resynchronization therapy was performed. Owing to biventricular synchronization and holding back reverse remodeling, the patient's symptoms were successfully alleviated, and he was discharged from the hospital.
\end{abstract}

Conclusions: Congestive heart failure is a rare complication in acromegaly-induced cardiomyopathy (occurs in only $3 \%$ of patients). Early diagnosis and treatment with curative drugs more than cardiovascular implantable electronic devices might lead to better surgical outcomes in this group of patients.

Keywords: Acromegalic cardiomyopathy, Heart failure, Cardiac resynchronization therapy

\section{Background}

Acromegaly presents with multisystem involvement, and cardiac manifestations remain an important cause of mortality $[1,2]$. Chronic excess of growth hormone (GH) and insulin-like growth factor 1 (IGF-1) leads to the development of acromegalic cardiomyopathy [3]. The clinical manifestations are biventricular hypertrophy, diastolic dysfunction, and in later stages may progress to systolic

\footnotetext{
* Correspondence: huyongmei2000@163.com

Affiliated with Chengdu Second People's Hospital, Qinyun South Road, 10th Avenue, Chengdu 610041, Sichuan, China
}

dysfunction and congestive heart failure [4]. Long-term treatments of acromegaly with pharmacological therapy, surgical treatment, and radiotherapy are extensively identified as standard regimens, among which surgical resection of the pituitary adenoma is often the first-line treatment [5]. In patients either waiting for or missing surgical indications due to severe heart failure, cardiac resynchronization therapy (CRT) might act as a desirable treatment to help synchronize cardiac contractility, improve symptoms, and reduce hospital admissions and mortality rates in patients

(c) The Author(s). 2019 Open Access This article is distributed under the terms of the Creative Commons Attribution 4.0 International License (http://creativecommons.org/licenses/by/4.0/), which permits unrestricted use, distribution, and reproduction in any medium, provided you give appropriate credit to the original author(s) and the source, provide a link to the Creative Commons license, and indicate if changes were made. The Creative Commons Public Domain Dedication waiver (http://creativecommons.org/publicdomain/zero/1.0/) applies to the data made available in this article, unless otherwise stated. 
with moderate to severe heart failure, hence ultimately creating chances for operation.

We report a case of a patient with acromegaly who was diagnosed with severe cardiac failure at the time of diagnosis and failed to recover cardiac function after pharmacotherapy and radiotherapy. Though successful resection of the pituitary adenoma was crucial, low left ventricular ejection fraction (LVEF) value in alignment with poor cardiac function could have made the surgery life-threatening. We applied mechanical therapy as CRT to this patient, which helped better control acromegalic cardiomyopathy, and this approach may create further chances for subsequent surgical resection.

\section{Case presentation}

A 49-year-old man with a history of acromegaly was admitted to our hospital with the concern of recurrent shortness of breath and dyspnea on exertion during the previous 2 years, and he had experienced an episode of presyncope 2 weeks prior without any further evaluation. He was a chef in a local restaurant for almost 30 years. He had no family history of any diseases and no past history of hypertension, diabetes mellitus, sleep apnea, or sudden cardiac death. He did not smoke or consume alcohol. The patient provided a history of stereotactic radiosurgeries twice in a decade or so and adherence to treatment with a somatostatin analog (octreotide given $40 \mathrm{mg}$ once per month through intramuscular injection) at the time of diagnosis 20 years before. The patient was overweight and moderately nourished. He was $1.85 \mathrm{~m}$ (73 inches) tall, weighed $134 \mathrm{~kg}$, and had a body mass index of $39 \mathrm{~kg} / \mathrm{m}^{2}$. His blood pressure was $110 / 60$ $\mathrm{mmHg}$, and his heart rate was 92 beats/min with sinus rhythm. He had distinct skeletal features that included prominent superciliary arches and nose bridge, enlargement of the tongue and lip, and large hands and feet. Cardiac auscultation revealed irregular premature beats and pathological third heart sound, and a systolic murmur was discovered over the apex and aortic area. Bilateral extensive borders of cardiac dullness were noted. His physiological reflexes were present without any pathology. An electrocardiogram demonstrated sinus rhythm with wide (160 ms) QRS duration of left bundle branch block (LBBB) (Fig. 1). The patient's condition was classified as New York Heart Association (NYHA) stage III-IV.

On admission, magnetic resonance imaging showed pituitary macroadenoma. Given the symptoms described, we arranged blood testing of myocardial injury markers showing an elevated brain natriuretic peptide level of $740 \mathrm{pg} / \mathrm{ml}$ indicating cardiac failure (Table 1). Hormone laboratory tests performed subsequently demonstrated excessive secretion of GH and IGF-1, twofold greater than the reference normal upper limit, which was consistent with pituitary macroadenoma (Table 2). Other routine analyses of liver and renal function were roughly normal.

A Holter monitor was ordered for underlying arrhythmias to explain the patient's dyspnea, chest discomfort, and presyncope. It demonstrated sinus rhythm with an average heart rate of 68 beats/min, frequent ventricular premature beats, and nonsustained ventricular tachycardia (up to $2200 \mathrm{~ms}$ ) (Fig. 2).

A chest $\mathrm{x}$-ray showed a cardiothoracic ratio (CTR) of $78 \%$. Echocardiography showed diffuse impairment of left ventricular (LV) systolic motion, reaching an LVEF of $16 \%$. We noted hypertrophy of the ventricular septum at $18 \mathrm{~mm}$, ventricular dilation, with LV diameter of $72 \mathrm{~mm}$. The right ventricle and atrium and the left atrium were also dilated with moderate mitral regurgitation and mild tricuspid regurgitation. There was no associated systolic anterior motion (SAM) of the mitral valve. Dyssynchrony of the biventricular systolic motion was apparent.

Given an exertional component to the symptoms together with echo presentations in order to better exclude ischemic cardiomyopathy, coronary angiography was performed, which showed normal coronary arteries without stenosis, and left ventriculography applied simultaneously revealed an EF of $20 \%$ with diffuse LV hypokinesis.

Given the patient's previous medical history of acromegaly, the absence of obstructive coronary artery imaging findings or segmental dyskinesia, family history of hypertrophic cardiomyopathy (HCM), symmetric hypertrophy, as well as absence of SAM of the mitral valve, acromegaly-induced cardiomyopathy was confirmed, which was absolutely opposed to coronary heart disease (CHD) and HCM.

These results indicated that it was probably not a case of hereditary cardiomyopathy; therefore, we diagnosed the patient as having secondary dilated cardiomyopathy due to acromegaly, even taking it a step further progressing to congestive heart failure secondary to acromegaly-induced dilated cardiomyopathy.

Chronic excess of GH and IGF-I secretion affects cardiac morphology and performance [5], so etiological treatment for acromegaly-induced cardiomyopathy is crucial to suppressing GH secretion or blocking GH action for the sake of reversing acromegaly-induced cardiomyopathy. The mainstay of treatment acknowledged globally is surgical resection of the pituitary adenoma [6], which was unfortunately considered high-risk given our patient's cardiac condition (NYHA stage III-IV). Although stereotactic radiosurgery combined with somatostatin analogs and GH antagonists administrated previously were effective in suppressing hormones, they could not help his cardiac function. Therefore, we carefully administered diuretics, vasodilators, angiotensin-converting enzyme inhibitor (ACEI), $\beta$-blockers, and spironolactone 


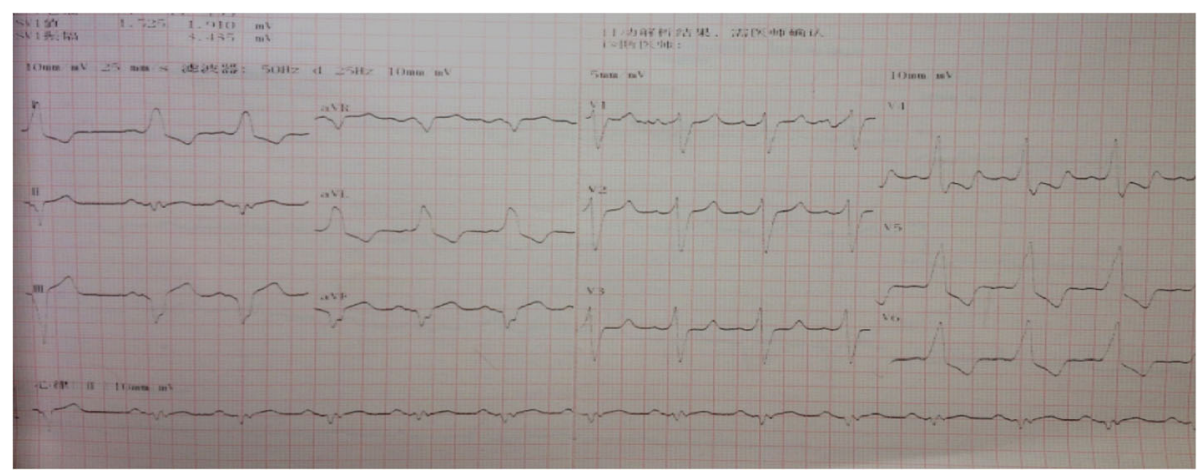

Fig. 1 Electrocardiogram on admission demonstrating sinus rhythm with wide (160 ms) QRS duration of left bundle branch block

for management of heart failure following the current guidelines [7]; in the meantime, octreotide $(200 \mu \mathrm{g} /$ day $)$ was administered for the control of GH excess. After good compliance of pharmacotherapy and a regular medical examination regimen for nearly half a year, the serum $\mathrm{GH}$ and IGF-1 concentrations decreased from $32.50 \mathrm{ng} / \mathrm{ml}$ to $1.98 \mathrm{ng} / \mathrm{ml}$ and $627.00 \mathrm{ng} / \mathrm{ml}$ to $229.10 \mathrm{ng} / \mathrm{ml}$, respectively, but the patient was hospitalized again because of uncontrollable cardiac failure. Accompanied by the normalization of GH and IGF-1 levels, the patient's cardiac function did not seem to take a favorable turn upon readmission. Though echocardiography showed a recovered $\mathrm{EF}$ value from $16 \%$ to $28 \%$, a significant ventricular mechanical dyssynchrony was detected as formerly. Electrophysiological study was performed using a nonaggressive stimulation protocol, which revealed a nonsustained ventricular monomorphic tachycardia [8]. In the presence of overt ventricular dyssynchrony, complete LBBB, LVEF $<35 \%$, inducible ventricular tachycardia, and symptomatic heart failure despite guideline-directed medical therapy, surgical indication was rarely assessed by neurosurgeons, and stereotactic radiosurgery together with pharmacotherapy produced infinitesimal effects. Therefore, we boldly recommended cardiac resynchronization therapy with defibrillator (CRT-D) implantation based on device implantation official guidelines [7, 9]. The patient underwent CRT insertion finally and was discharged to home 5 days later, pharmacotherapy continued as usual (Fig. 3).

Table 1 Myocardial injury markers on admission

\begin{tabular}{ll}
\hline Measured value & Reference range \\
\hline CK-MB mass $<1.0 \mathrm{ng} / \mathrm{ml}$ & $0-4.3 \mathrm{ng} / \mathrm{ml}$ \\
Myoglobin $50.8 \mathrm{ng} / \mathrm{ml}$ & $0-107 \mathrm{ng} / \mathrm{ml}$ \\
Troponin I $0.07 \mathrm{ng} / \mathrm{ml}$ & $0-0.40 \mathrm{ng} / \mathrm{ml}$ \\
BNP $740 \mathrm{pg} / \mathrm{ml}$ & $0-100 \mathrm{pg} / \mathrm{ml}$ \\
D-dimer $723 \mathrm{ng} / \mathrm{ml}$ & $0-600 \mathrm{ng} / \mathrm{ml}$ \\
\hline
\end{tabular}

BNP Brain natriuretic peptide, $C K-M B$ Creatine kinase $M B$
Telephone follow-up was arranged, and the patient claimed symptom improvement following the device insertion 1 month later and was basically back to normal life. We required that he return for follow-up at 1 month, 3 months, and 6 months after the interventional therapy. The patient has been followed in our outpatient clinic for nearly half a year now. During his last visit, echocardiography identified improved LVEF of $54 \%$, and a chest $\mathrm{x}$-ray showed reduced CTR of $60 \%$. The patient was in NYHA functional class II (Fig. 4).

\section{Discussion and conclusions}

We present a case of a patient with acromegaly who had clinical signs and symptoms of refractory decompensated heart failure, diagnosed as congestive heart failure (CHF) and attributed to acromegaly-induced dilated cardiomyopathy. He eventually had a dramatic response to medical device therapy. This case reinforces the importance of careful examination, accurate diagnosis, detailed evaluation, and searching for better alternative treatments when standard therapy initially fails.

Acromegaly is a rare endocrine disorder with an incidence of 3 per 1 million per year [1]. Acromegaly is characterized by chronic GH and IGF-1 hypersecretion that leads to an increased mortality rate, with cardiovascular complications accounting for the highest number of patient deaths $[2,4,6]$. GH exerts its effects by stimulating the production of IGF-I either directly or indirectly, which

Table 2 Initial hormone laboratory tests

\begin{tabular}{lll}
\hline & Measured value & Reference range \\
\hline GH & $32.5 \mathrm{ng} / \mathrm{ml}$ & $0-2.10 \mathrm{ng} / \mathrm{ml}$ \\
IGF-1 & $627.0 \mathrm{ng} / \mathrm{ml}$ & $117.0-329.2 \mathrm{ng} / \mathrm{ml}$ \\
TSH & $0.852 \mathrm{mlU} / \mathrm{L}$ & $0.35-4.94 \mathrm{mlU} / \mathrm{L}$ \\
fT4 & $14.80 \mathrm{pmol} / \mathrm{L}$ & $9.00-19.00 \mathrm{pmol} / \mathrm{L}$ \\
PRL & $8.60 \mathrm{ng} / \mathrm{ml}$ & $3.6-16.3 \mathrm{ng} / \mathrm{ml}$ \\
\hline
\end{tabular}

Abbreviations: fT4 Free thyroxine, GH Growth hormone, IGF-1 Insulin-like growth factor 1, PRL Prolactin, TSH Thyroid-stimulating hormone 


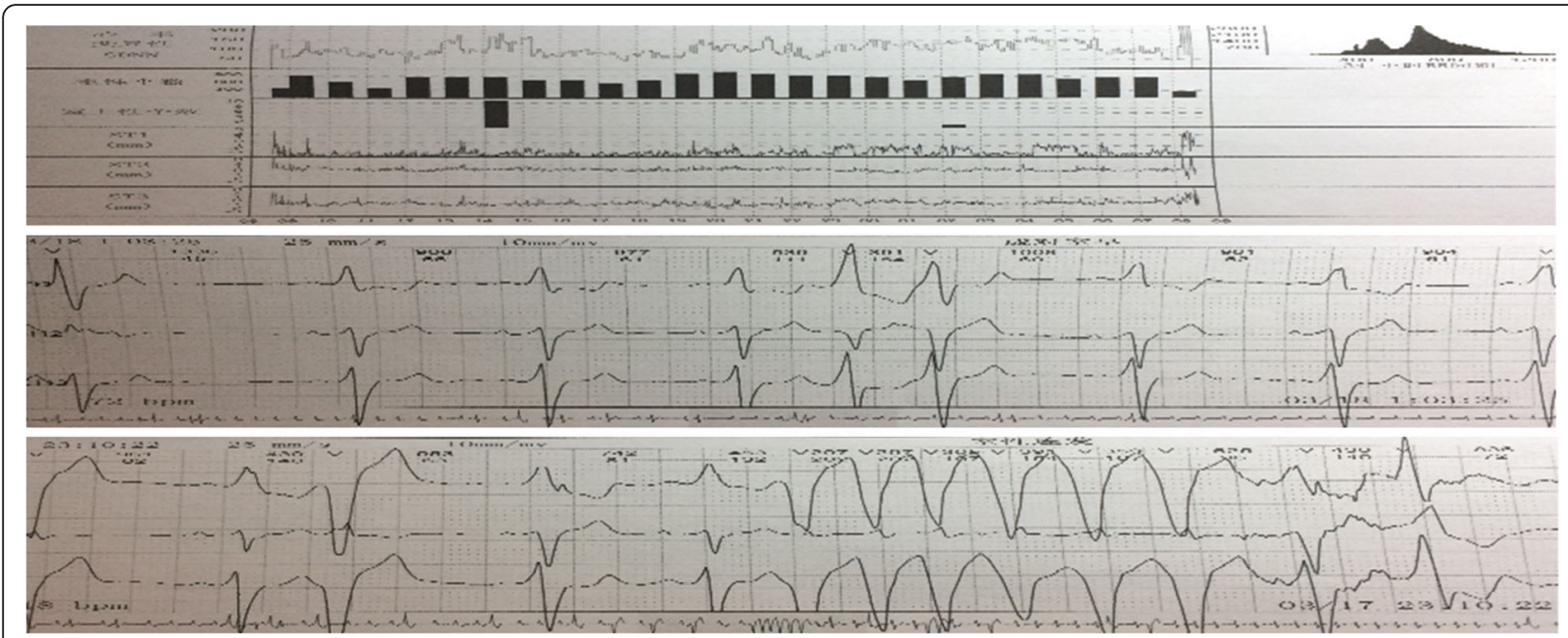

Fig. 2 Dynamic electrocardiogram showing frequent ventricular premature beats and nonsustained ventricular tachycardia

mediates GH action on peripheral tissues. The GH/IGF-1 axis acts through increasing biological protein synthesis, cardiomyocyte size, and muscle-specific gene expression. Specifically, IGF-1 promotes cardiac hypertrophy and increases muscle-specific gene transcription (namely, troponin I, myosin light chain 2 , and $\alpha$-actin) $[10,11]$. Chronic excess of these hormones leads to the development of acromegalic cardiomyopathy, which in early stages manifests biventricular hypertrophy, diastolic dysfunction, and later may progress to systolic dysfunction and eventually congestive heart failure [3]. Heart failure from acromegalic cardiomyopathy is one of the most common causes of death in acromegaly and is now receiving increasing attention. The GH/IGF-1 axis regulates cardiac growth, stimulates myocardial contractility, and influences the vascular system. Epidemiological evidence suggests that serum IGF-1 levels in the low-normal range are associated with increased risk of acute myocardial infarction, ischemic heart disease, coronary and carotid artery atherosclerosis, and stroke [12-14]. Among histological abnormalities induced by the hormones, the most relevant is a proliferation of myocardial fibrous tissue leading to progressive interstitial remodeling and deterioration of diastolic and systolic cardiac performance [15]. In acromegaly, chronic GH/IGF-I excess causes a concentric cardiac hypertrophy associated with diastolic dysfunction. In later stages, impaired systolic function ending in heart failure

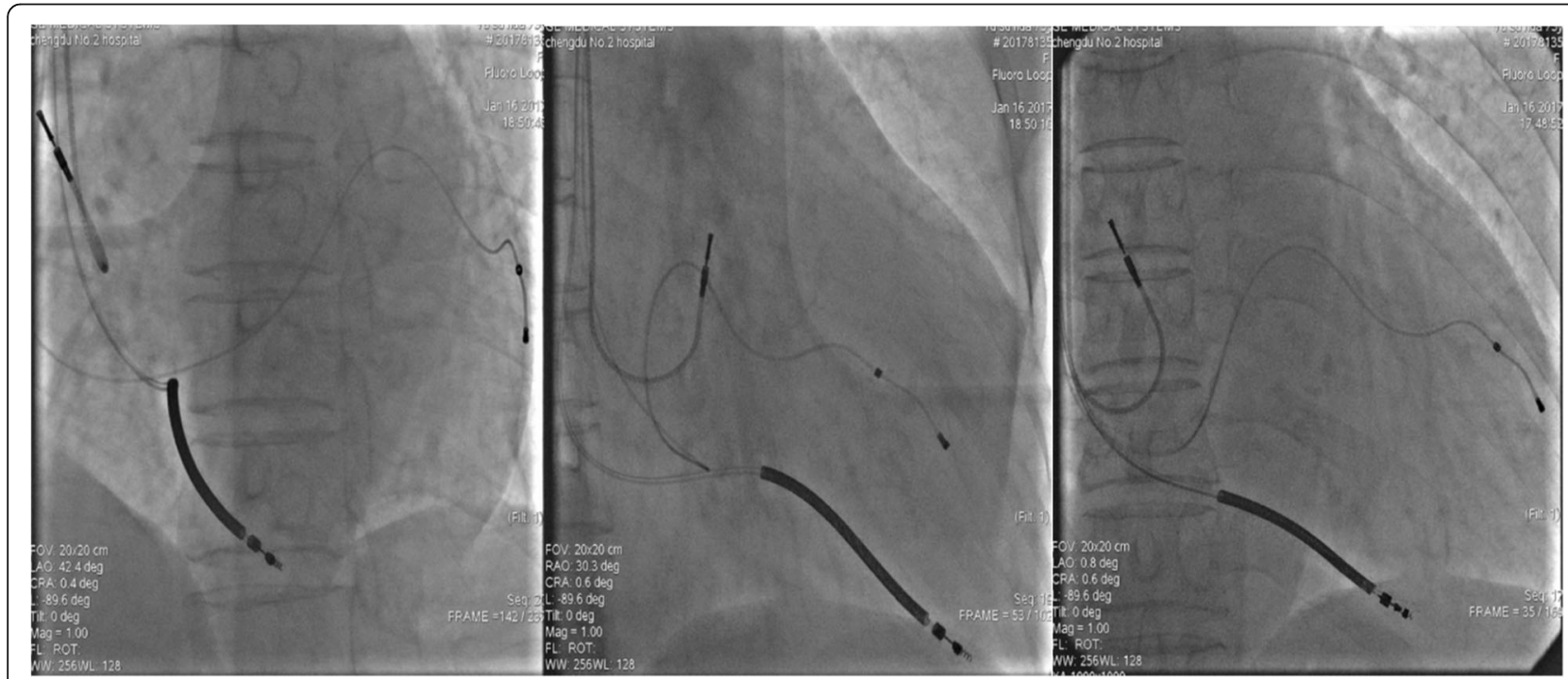

Fig. 3 Cardiac resynchronization therapy electrode position in LAO 45 degrees, RAO 30 degrees, AP view. LAO Left anterior oblique, RAO Right anterior oblique, AP Anteroposterior position 


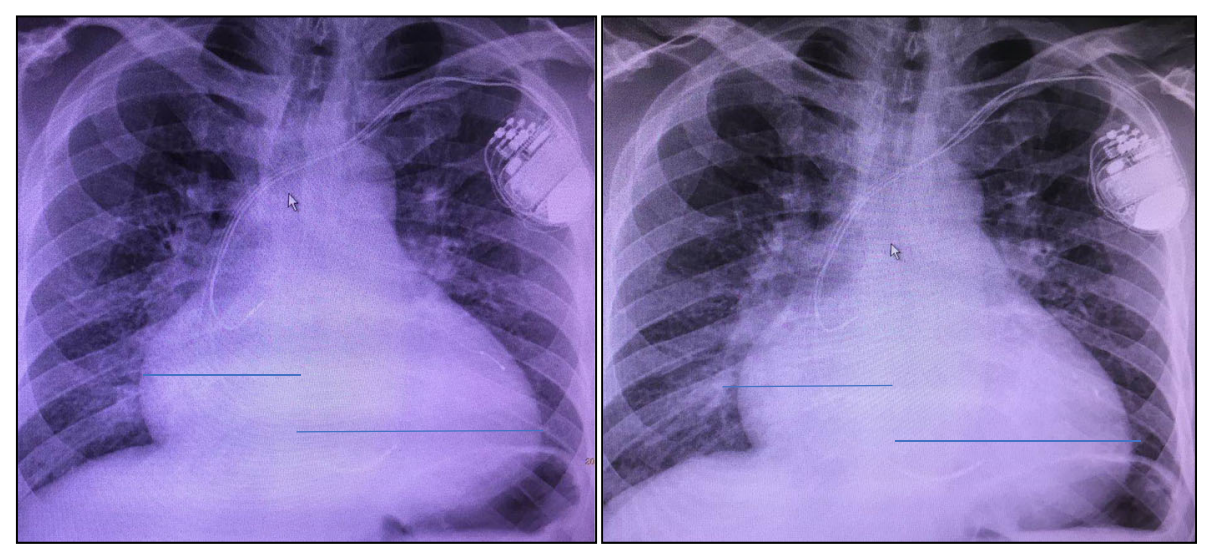

Fig. 4 Chest $x$-rays at 1 month (left) and 6 months (right) after cardiac resynchronization therapy implantation, during follow-up visits

may occur. Abnormalities of cardiac rhythm (such as premature beats, paroxysmal atrial fibrillation, paroxysmal supraventricular tachycardia, sick sinus syndrome, ventricular tachycardia, and bundle branch blocks) and of cardiac valves (the most frequent being mitral and aortic abnormalities associated with LV hypertrophy) can also occur [15-17]. The yearly incidence of acromegaly is estimated to be between 3 and 4 cases per 1 million people per year. The average age at diagnosis is 40 to 45 years $[18,19]$, and our 49 -year-old patient was nearly in that age range.

Current treatments aim to normalize GH and IGF-1 secretion levels in patients with acromegaly for the sake of reversing some of the morphological changes in the early stage, regression of cardiac hypertrophy and improvement of cardiac dysfunction [4, 18-20]. Different strategies for management can be divided into two components, namely to control GH and IGF-1 hypersecretion and cardiac heart failure. The normalization of GH and IGF-1 levels, whether by surgical or pharmacological therapy, is essential to reversing or arresting cardiovascular complications [5]. An earlier case report described a 43-year-old man with severe congestive heart failure produced by acromegalic cardiomyopathy who recovered significantly through octreotide followed by transsphenoidal surgery [21]. Some reports suggest that the beneficial effects obtained from hormone suppression therapy appear more significant in younger patients with short disease duration than in older patients [22]. Other reports describe how the classic treatments of acromegaly, including surgical resection of the pituitary adenoma, somatostatin analogs and GH antagonists, and stereotactic radiosurgery or fractionated radiation, might improve cardiac function in the short term but probably have very little effect on long-term prognosis [23, 24]. Successful later case reports support the idea of the use of traditional heart failure therapy, which consists of ACEIs, angiotensin receptor blockers, $\beta$-blockers, aldosterone antagonists, and diuretics, to further improve cardiovascular function because GH/IGF-1 control alone is insufficient $[25,26]$. Heart transplant is an option for end-stage heart failure [24, 27]. Considering our patient's minimal response to these acknowledged treatments mentioned above, we carefully selected CRT in this patient, and his cardiac function recovered considerably with our elaborate care. At his follow-up visits, the patient has been in good condition, with various gradually improved cardiac function indexes.

CRT is an effective and well-established therapy for patients with heart failure, LV systolic dysfunction (LVEF $\leq 35 \%$ ), and electrical dyssynchrony, demonstrated by a surface QRS duration of $\geq 130 \mathrm{~ms}$ [7]. It appears that CRT offers a more favorable response with regard to reverse LV remodeling in cases of nonischemic cardiomyopathy $[28,29]$. The use of mechanical therapies including CRT/CRT-D implantation have not been adequately studied in acromegalic heart failure, and the long-term prognosis of CHF in patients with acromegaly remains poor. This group of patients might benefit from device therapies that restore ventricular systolic synchrony and ameliorate ventricular reverse remodeling.

\section{Abbreviations \\ ACEl: Angiotensin-converting enzyme inhibitor; BNP: Brain natriuretic peptide; CHF: Congestive heart failure; CRT: Cardiac resynchronization therapy; CRT- D: Cardiac resynchronization therapy with defibrillator; CTR: Cardiothoracic ratio; GH: Growth hormone; HCM: Hypertrophic cardiomyopathy; IGF-1: Insulin-like growth factor 1; LBBB: Left bundle branch block; LV: Left ventricular; LVEF: Left ventricular ejection fraction; MR: Mitral regurgitation; NYHA: New York Heart Association; SAM: Systolic anterior motion}

\section{Acknowledgements}

Special thanks to the department of endocrinology, which assisted in the treatment of this patient.

Funding

No funding was received for this study.

Availability of data and materials

The authors agree to make the raw data and materials described in our manuscript freely available. 


\section{Authors' contributions}

JW was the major contributor in writing the manuscript. JW, YH, JL, and XL followed the patient clinically. YH and $J$ supervised the whole work. All authors read and approved the final manuscript.

\section{Ethics approval and consent to participate} Not applicable.

\section{Consent for publication}

Written informed consent was obtained from the patient for publication of this case report and any accompanying images. A copy of the written consent is available for review by the Editor-in-Chief of this journal.

\section{Competing interests}

The authors declare that they have no competing interests.

\section{Publisher's Note}

Springer Nature remains neutral with regard to jurisdictional claims in published maps and institutional affiliations.

Received: 4 August 2018 Accepted: 25 February 2019

Published online: 25 April 2019

\section{References}

1. Holdaway IM, Rajasoorya C. Epidemiology of acromegaly. Pituitary. 1999:2:29-41.

2. Vitale G, Pivonello R, Galderisi M, et al. Cardiovascular complications in acromegaly: methods of assessment. Pituitary. 2001:4:251-7.

3. Saccà L, Napoli R, Cittadini A. Growth hormone, acromegaly, and heart failure: an intricate triangulation. Clin Endocrinol. 2003;59(6):660-71.

4. Matta MP, Caron P. Acromegalic cardiomyopathy: a review of the literature. Pituitary. 2003;6(4)):203-7.

5. Mosca S, Paolillo S, Colao A, Bossone E, Cittadini A, ludice FL, Parente A, Conte S, Rengo G, Leosco D, Trimarco B, Filardi PP. Cardiovascular involvement in patients affected by acromegaly: an appraisal. Int J Cardiol. 2013;167:1712-8

6. Vitale G, Pivonello R, Lombardi G, Colao A. Cardiac abnormalities in acromegaly: pathophysiology and implications for management. Treat Endocrinol. 2004;3:309-18.

7. Ponikowski P, Voors AA, Anker SD, et al. 2016 ESC guidelines for the diagnosis and treatment of acute and chronic heart failure: the Task Force for the diagnosis and treatment of acute and chronic heart failure of the European society of cardiology (ESC). Developed with the special contribution of the Heart failure association (HFA) of the ESC. Eur Heart J. 2016;37:2129-200.

8. Nazari N, Keykhavani A, Sayah S, Hekmat M, Golabchi A, Rad MA, Alizadeh A, Heidarali M. Role of electrophysiological study in patients with syncope and bundle branch block. J Res Med Sci. 2014;19(10):961-4.

9. Brignole M, Auricchio A, Baron-Esquivias G, et al. 2013 ESC guidelines on cardiac pacing and cardiac resynchronization therapy: the Task Force on cardiac pacing and resynchronization therapy of the European society of cardiology (ESC). Developed in collaboration with the European heart rhythm association (EHRA). Eur Heart J. 2013;34:2281-329.

10. Butt RP, Laurent GJ, Bishop JE. Collagen deposition and replication by cardiac fibroblasts is enhanced in response to diverse classes of growth factors. Eur J Cell Biol. 1995;68:330-5.

11. Brüel $A$, Oxlund $H$. Biosynthetic growth hormone increase the collagen deposition rate in rat aorta and heart. Eur J Endocrinol. 1995;132:195-9.

12. Juul A, Scheike T, Davidsen M, Gyllenborg J, Jorgensen T. Low serum insulin-like growth factor I is associated with increased risk of ischemic heart disease: a population-based case-control study. Circulation. 2002;106:939-44.

13. Johnsen SP, Hundborg HH, Sørensen HT, Orskov H, Tjønneland A, Overvad K, Jørgensen JO. Insulin-like growth factor (IGF) I, -II, and IGF binding protein-3 and risk of ischemic stroke. J Clin Endocrinol Metab. 2005;90: 5937-41.

14. Vasan RS, Sullivan LM, D'Agostino RB, Roubenoff R, Harris T, Sawyer DB, Levy D, Wilson PW. Serum insulin-like growth factor I and risk for heart failure in elderly individuals without a previous myocardial infarction: the Framingham Heart Study. Ann Intern Med. 2004;139:642-8.

15. Kahaly G, Olshausen KV, Mohr-Kahaly S, Erbel R, Boor S, Beyer J, Meyer J. Arrhythmia profile in acromegaly. Eur Heart J. 1992;13:51-6.
16. Colao A, Spinelli L, Marzullo P, Pivonello R, Petretta M, Di Somma C, Vitale G, Bonaduce D, Lombardi G. High prevalence of cardiac valve disease in acromegaly: an observational analytical prospective case-control study. J Clin Endocrinol Metab. 2003:88:3196-201.

17. Pereira AM, van Thiel SW, Lindner JR, Roelfsema F, van der Wall EE, Morreau H, Smit JW, Romijn JA, Bax JJ. Increased prevalence of regurgitant valvular heart disease in acromegaly. J Clin Endocrinol Metab. 2004;89:71-5.

18. Sharma AN, Tan M, Amsterdam EA, Singh GD. Acromegalic cardiomyopathy: epidemiology, diagnosis, and management. Clin Cardiol. 2018;41(3):419-25.

19. Melmed S. Medical progress: acromegaly. N Engl J Med. 2006;355:2558-73.

20. Dal J, Feldt-Rasmussen U, Andersen M, et al. Acromegaly incidence, prevalence, complications and long-term prognosis: a nationwide cohort study. Eur J Endocrinol. 2016;175:181-90.

21. Shimakura A, Miyakoshi H, Ohkuwa H, Kitabayashi M, Komai T, Hisada A, Aoki K, Sakagami S, Kobayashi K, Takata S. Improvement of cardiac function after treatment with octreotide followed by trans-sphenoidal surgery in an acromegalic patient who presented with congestive heart failure. Jpn Heart J. 2002;43(1):69-77.

22. Colao A, Vitale G, Pivonello R, Ciccarelli A, Di Somma C, Lombardi G. The heart: an end-organ of GH action. Eur J Endocrinol. 2004;151(Suppl 1):S93-101.

23. Bihan $\mathrm{H}$, Espinosa $\mathrm{C}$, Valdes-Socin $\mathrm{H}$, et al. Long-term outcome of patients with acromegaly and congestive heart failure. J Clin Endocrinol Metab. 2004;89:5308-13.

24. MacCarthy P, Kearney M, Nolan J, et al. Prognosis in heart failure with preserved left ventricular systolic function: prospective cohort study. BMJ. 2003;327:78-9.

25. Thomas J, Dattani A, Zemrak F, et al. Renin-angiotensin system blockade improves cardiac indices in acromegaly patients. Exp Clin Endocrinol Diabetes. 2017;125:365-7.

26. Schwarz ER, Jammula P, Gupta R, et al. A case and review of acromegalyinduced cardiomyopathy and the relationship between growth hormone and heart failure: cause or cure or neither or both? J Cardiovasc Pharmacol Ther. 2006:11:232-44.

27. Albat B, Leclercq F, Serre I, Fille A, Baldet P, Grolleau-Raoux R, Thevenet A. Heart transplantation for terminal congestive heart failure in an acromegalic patient. Eur Heart J. 1993;14(11):1572-5.

28. Barra S, Looi KL, Gajendragadkar PR. Applicability of a risk score for prediction of the long-term benefit of the implantable cardioverter defibrillator in patients receiving cardiac resynchronization therapy. Europace. 2016;18:1187-93.

29. Ogano M, Iwasaki YK, Tanabe J, Takagi H, Umemoto T, Hayashi M, Miyauchi Y, Shimizu W. Cardiac resynchronization therapy restored ventricular septal myocardial perfusion and enhanced ventricular remodeling in patients with nonischemic cardiomyopathy presenting with left bundle branch block. Heart Rhythm. 2014;11(5):836-41.

Ready to submit your research? Choose BMC and benefit from

- fast, convenient online submission

- thorough peer review by experienced researchers in your field

- rapid publication on acceptance

- support for research data, including large and complex data types

- gold Open Access which fosters wider collaboration and increased citations

- maximum visibility for your research: over $100 \mathrm{M}$ website views per year

At BMC, research is always in progress.

Learn more biomedcentral.com/submissions 